\title{
Letramento informacional e o trabalho do bibliotecário frente às demandas e necessidades informacionais dos estudantes das bibliotecas do Instituto Federal do Espírito Santo
}

\author{
Information literacy and the work of the librarian facing the informational demands and \\ needs of the students of the libraries of the federal Institute of Espirito Santo
}

Kelly Rita de Azevedo Mestra em Ciência da Informação pelo Programa de de Pós-Graduação em Ciência da Informação da Universidade Federal de Minas Gerais - UFMG, Brasil. Bibliotecária/Documentalista no Instituto Federal do Espírito Santo - IFES, Brasil.

E-mail: kellybibli@gmail.com https://orcid.org/0000-0001-6908-1206

\author{
Ligia Maria Moreira Dumont \\ Doutora em Ciência da Informação pelo Programa de Pós-Graduação em Ciência da Informação da \\ Universidade Federal do Rio de Janeiro - UFRJ, Brasil. \\ Professora titular do Departamento de Teoria e Gestão da Informação da Escola de Ciência da Informação da \\ Universidade Federal de Minas Gerais - UFMG, Brasil. \\ E-mail: dumont@eci.ufmg.br \\ https://orcid.org/0000-0001-5047-1415
}

\section{Resumo}

Busca identificar o papel do bibliotecário no desenvolvimento do letramento informacional de estudantes do Instituto Federal do Espírito Santo (Ifes) frente às necessidades e demandas de informações. A pesquisa acadêmica foi classificada como descritiva, estabelecendo em seu desenho o estudo de caso como método. Instituiu-se como recorte de pesquisa duas bibliotecas que contemplassem condições e realidades socioculturais e demográficas diversificadas de estudantes e a análise dos dados empíricos por meio dos métodos quantitativo e qualitativo, tendo como enfoque de análise os estudantes e os bibliotecários pertencentes a essas bibliotecas. Como resultado, verificou-se que os bibliotecários entrevistados possuem conhecimento da importância do letramento informacional e desenvolvem algumas atividades, quando há demanda dos usuários. Averiguou-se também que não há o planejamento para a formação de usuários e de ações específicas para todos os públicos que visam o letramento informacional, bem como de trabalho integrado entre dirigentes, equipe pedagógica, professores e bibliotecários. Depreende-se pela pesquisa que tais ausências têm como pano de fundo o fato da equipe pedagógica e professores desconhecerem o papel educativo do bibliotecário, além da ausência de atividades integradas entre os professores e bibliotecários, tendo como objetivo comum melhorar de forma efetiva o desenvolvimento dos estudantes no processo de aprendizagem dentro e fora da sala de aula. Quanto aos estudantes, a contribuição valorosa nas respostas traz luz ao caminho que ainda precisa ser percorrido pelo bibliotecário para o desenvolvimento do letramento informacional direcionado ao segmento discente.

Palavras-chave: Letramento informacional. Serviços de informação - educação de usuários. Instituto Federal do Espírito Santo. Bibliotecas. Bibliotecários. 


\begin{abstract}
It seeks to identify the role of the librarian in the development of information literacy of students of the Federal Institute of Espírito Santo (IFES) facing the needs and demands of information. The academic research was classified as descriptive, establishing in its design the case study as a method. It was set up as a research clipping two libraries that contemplated diverse socio-cultural and demographic conditions and realities of students and the analysis of empirical data through quantitative and qualitative methods, focusing on the students and librarians belonging to these libraries. As a result, it was found that the interviewed librarians are aware of the importance of information literacy and develop some activities when there are demands from users. It was also found that there is no planning of user training and specific actions for all audiences aimed at information literacy, as well as integrated work between leaders, pedagogical staff, teachers and librarians. It appears from the research that such absences have as a background the fact that the pedagogical team and teachers are unaware of the educational role of the librarian, in addition to the absence of integrated activities between teachers and librarians, with the common objective of effectively improving students development in the learning process inside and outside the classroom. As for students, the valuable contribution in the answers sheds light on the path that still needs to be followed by the librarian for the development of information literacy directed to the student segment.
\end{abstract}

Keywords: Information literacy. Information services - user education. Institute Federal of Espírito Santo. Libraries. Librarian.

\title{
1. Introdução
}

Há certa trivialidade em se afirmar que a informação é cada vez mais reconhecida como valor estratégico, seja pelas pessoas em geral ou os gerentes das mais variadas instituições do governo, empresas públicas e privadas, escolas ou universidades. O acesso e a produção de informação relevante e oportuna tornaram-se indispensáveis e necessários, não apenas para o gerenciamento das instituições, para o ensino e o aprendizado formal, mas também para as pessoas, pois elas sentem a necessidade de estar bem informadas no seu dia-a-dia, seja por questões pessoais ou profissionais. Paradoxalmente à explosão da informação disponível, surgiram inúmeras barreiras para o seu acesso, busca e recuperação, devido à forma de organização e disponibilização da informação nos mais diversos formatos. O grande volume de informação provocado pelos avanços nos campos científicos e tecnológicos, a produção imensurável de fontes de informação, o desconhecimento dos mecanismos de busca e filtragem da informação, os avanços das tecnologias da informação, o preço, dentre outras situações do cotidiano podem inviabilizar que a informação possa ser acessada e se transformar eventualmente em conhecimento.

Nesse contexto, caracterizado por uma abundância informacional, é necessário que os indivíduos desenvolvam habilidades específicas para lidar com a informação. Tal conjunto de habilidades, conhecimentos e atitudes, fez surgir na Biblioteconomia a competência informacional, ou letramento informacional, termo traduzido da expressão information literacy 
e cunhado nos Estados Unidos, na década de 1970. Tal tema tem despertado o interesse dos profissionais de informação, em particular o bibliotecário, por trabalhar com a informação no seu cotidiano, com destaque para o papel importante como educadores, especialmente nas escolas e universidades (CAMPELLO, 2003).

O presente artigo é fruto de uma pesquisa acadêmica, ${ }^{1}$ que investigou o desenvolvimento do letramento informacional dos estudantes do Instituto Federal do Espírito Santo (Ifes), suas demandas e necessidades informacionais e o trabalho do bibliotecário presente nas bibliotecas dos campi do Instituto. A escolha em pesquisar os estudantes se deu pelo interesse em conhecer melhor o maior público que utiliza as bibliotecas do Ifes, além do desafio de trabalhar com um público com perfis e necessidades informacionais distintas matriculados nas diferentes modalidades de ensino existente em um mesmo ambiente acadêmico.

O Ifes é uma instituição pluricurricular e multicampi (reitoria, campus, campus avançado, polo de inovação e polos de educação à distância) especializada na oferta de educação profissional e tecnológica (EPT) em todos os seus níveis e formas de articulação (ensino médio integrado; técnico concomitante e subsequente; licenciaturas, bacharelados e pós-graduação stricto sensu e lato sensu). Com 22 campi em funcionamento, incluindo o Centro de Referência em Formação e em Educação a Distância (Cefor), o Ifes se faz presente em todas as microrregiões capixabas. Destaca-se, ainda, que em algumas localidades a biblioteca dos campi é a única disponível aberta também ao público externo. Tal diversidade de usuários atendidos cunhou para essas bibliotecas a designação de bibliotecas multiníveis, observada em algumas publicações sobre tais características.

A pesquisa se realizou em duas bibliotecas previamente escolhidas entre os 22 campi em funcionamento do Ifes. A escolha da amostra foi intencional e baseou-se nos seguintes critérios: bibliotecas que contemplam condições e realidades socioculturais e demográficas diversificadas de estudantes; campi com aspectos histórico-geográficos relevantes (localização geográfica, data de fundação); maior diversidade de oferta de cursos nas modalidades de ensino presentes no Instituto; tempo de funcionamento das bibliotecas nos respectivos campi.

\footnotetext{
${ }^{1}$ Pesquisa de mestrado desenvolvida no Programa de Pós-graduação em Ciência da Informação da Escola de Ciência da Informação da UFMG (AZEVEDO, 2020).
} 
Pesquisar o tema letramento informacional, levando em consideração o contexto da educação de usuários dos estudantes do Ifes, é uma oportunidade de contribuir com conhecimentos sobre os serviços e ações formativas oferecidos pelas bibliotecas e como os bibliotecários podem influenciar no desenvolvimento das habilidades e atitudes informacionais dos usuários na busca das informações, uma vez que certa parcela deste público não teve acesso às bibliotecas, seja por inexistirem na sua vivência anterior, por falta de incentivo ou até mesmo de interesse.

\section{Fundamentação teórico-conceitual}

Fundamentos e conceitos teóricos, acrescidos de experiências anteriores, são fundamentais para o desenvolvimento de toda pesquisa acadêmica. Como a proposição desta investigação se refere a temas de grande relevância para a Biblioteconomia e a Ciência da Informação na atualidade, os quais vêm se modificando, burilando e expandindo seus objetivos e alcances a passos largos, a fundamentação da pesquisa buscou se concentrar na literatura da última década, sem descartar as de valor fundamental. As referências ora apresentadas são um extrato das que deram aporte fundamental teórico à pesquisa.

\subsection{Information literacy: o delineamento dos conceitos}

A trajetória do information literacy teve início com a implementação dos serviços de referências e educação dos usuários em bibliotecas, cujo objetivo principal era auxiliar os leitores a entender a estrutura peculiar daquele espaço e as fontes de informação, constituindo um passo à frente na trajetória da profissão bibliotecária na busca de maior espaço para exercer seu papel educativo. A expressão information literacy foi utilizada pela primeira vez nos Estados Unidos no início da década de 1970 e fazia menção somente às habilidades necessárias que uma pessoa teria que ter em relação ao uso da informação eletrônica que estava sendo comercializada naquele país desde a década de 1960 (CAMPELLO, 2009a).

No Brasil, os estudos sobre information literacy emergiram no início do século XXI. A literatura mostra o uso do termo e suas diversas traduções, quais sejam: letramento informacional, alfabetização informacional, habilidade informacional e competência informacional, para se referir praticamente à mesma ideia. Na Espanha, a tradução mais usada 
é alfabetização informacional, e em Portugal, literacia da informação. Os referidos termos estão relacionados, mas representam eventos, processos e ideias que apresentam diferenças de nuances. Utilizou-se a literatura da área para analisar os termos e estruturar um arcabouço conceitual do letramento informacional.

Ainda no que diz respeito às traduções que o termo information literacy tem na literatura científica brasileira, assim como as diferenças dos referidos conceitos, destaca-se que tais traduções são apresentadas fundamentadas nas pesquisas desenvolvidas nas áreas de Educação e Ciência da Informação. Sobre essa afirmação, Gasque (2010, p. 84) diz que:

\begin{abstract}
Embora esses conceitos (competência informacional, letramento informacional, competência em informação, habilidade informacional e alfabetização informacional) estejam relacionados entre si, não devem ser empregados como sinônimos, na medida em que representam ações, eventos e ideias distintos. Essa limitação terminológica reflete a natureza emergente do tema, o que implica uma definição mais precisa dos conceitos relacionados à questão em causa para que seja possível a utilização do mesmo referencial de representação.
\end{abstract}

Ainda segundo a autora, a expressão "letramento informacional constitui um processo que integra as ações de localizar, selecionar, acessar, organizar, usar a informação e gerar conhecimento, visando à tomada de decisão e à resolução de problemas" (GASQUE, 2010, p. $83)$.

A ampliação da função educativa do bibliotecário aliada ao surgimento de novas demandas para a formação de pessoas com habilidades em lidar com a informação nos mais variados suportes, fez com que o papel do bibliotecário na escola expandisse para uma nova função emergente. Essa ação tem sido sustentada por pesquisas tanto da área de Biblioteconomia e Ciência da Informação, como da Educação e também pela prática do serviço de orientação de usuários nas escolas, o que propiciou o aparecimento do conceito de letramento informacional (CAMPELLO, 2009b).

Na literatura da área de educação, desde a década de 1980 o termo letramento vem sendo estudado. Segundo Soares (2009), letramento é a tradução da expressão inglesa literacy e expressa o estado ou condição que assume aquele que aprende a ler e escrever, sendo importante o ato do letramento na educação como ato de direito humano absoluto e o reconhecimento dos múltiplos significados que o letramento conduz a uma diversidade de definições operacionais. Montiel-Overall (2005) relata que a colaboração é amplamente promovida na educação como uma forma de melhorar o ensino e a aprendizagem e envolve professores, diretores, educadores 
especiais, pais e outras comunidades escolares. Contudo, notoriamente ausentes da literatura na educação estão as discussões envolvendo a colaboração entre professores e bibliotecários.

Assim, para melhor esclarecer as diferenças entre os conceitos relativos ao information literacy no contexto brasileiro, Gasque (2013, p. 5) fez uma breve definição do termo (quadro 1) ressaltando que o "[...] letramento informacional é um tópico de estudo relativamente novo e, por isso, tem suscitado discussões terminológicas, em especial, em relação à tradução dos conceitos da língua inglesa para o português do Brasil”.

Quadro 1 - Information literacy - conceitos

\begin{tabular}{|c|c|}
\hline Termo & Conceituação \\
\hline Letramento informacional & $\begin{array}{l}\text { Processo de aprendizagem voltado para o desenvolvimento de competências } \\
\text { para buscar e usar a informação na resolução de problemas ou tomada de } \\
\text { decisões. O letramento informacional é um processo investigativo, que } \\
\text { propicia o aprendizado ativo, independente e contextualizado; o pensamento } \\
\text { reflexivo e o aprender a aprender ao longo da vida. Pessoas letradas têm } \\
\text { capacidade de tomar melhores decisões por saberem selecionar e avaliar as } \\
\text { informações e transformá-las em conhecimento aplicável. }\end{array}$ \\
\hline Alfabetização informacional & $\begin{array}{l}\text { Refere-se à primeira etapa do letramento informacional, isto é, abrange os } \\
\text { contatos iniciais com as ferramentas, produtos e serviços informacionais. } \\
\text { Nessa etapa, o indivíduo desenvolve noções, por exemplo, sobre a } \\
\text { organização de dicionários e enciclopédias, de como as obras são produzidas, } \\
\text { da organização da biblioteca e dos significados do número de chamada, } \\
\text { classificação, índice, sumário, autoria, bem como o domínio das funções } \\
\text { básicas do computador - uso do teclado, habilidade motora para usar o } \\
\text { mouse, dentre outros. O ideal é que a alfabetização informacional se inicie } \\
\text { na educação infantil. }\end{array}$ \\
\hline Competência informacional & $\begin{array}{l}\text { Refere-se à capacidade do aprendiz de mobilizar o próprio conhecimento que } \\
\text { o ajuda a agir em determinada situação. Ao longo do processo de letramento } \\
\text { informacional, os aprendizes desenvolvem competências para identificar a } \\
\text { necessidade de informação, avaliá-la, buscá-la e usá-la eficaz e } \\
\text { eficientemente, considerando os aspectos éticos, legais e econômicos. }\end{array}$ \\
\hline Habilidade informacional & $\begin{array}{l}\text { Realização de cada ação específica e necessária para alcançar determinada } \\
\text { competência. Para o aprendiz ser competente em identificar as próprias } \\
\text { necessidades de informação, por exemplo, é necessário desenvolver } \\
\text { habilidades de formular questões sobre o que deseja pesquisar, explorar } \\
\text { fontes gerais de informação para ampliar o conhecimento sobre o assunto, } \\
\text { delimitar o foco, identificar palavras-chave que descrevem a necessidade de } \\
\text { informação, dentre outras. }\end{array}$ \\
\hline
\end{tabular}

Fonte: GASQUE (2013)

Ainda no que diz respeito ao letramento informacional, Siqueira; Siqueira (2012), demonstram, por meio de mapa conceitual (Figura 1), que o termo apresenta cinco características, sendo elas: 'localizar', 'selecionar', 'acessar', 'organizar' e ‘usar a informação', tendo como objetivo tanto a tomada de decisão como a geração de conhecimento. 
Figura 1 - Mapa conceitual de Letramento Informacional

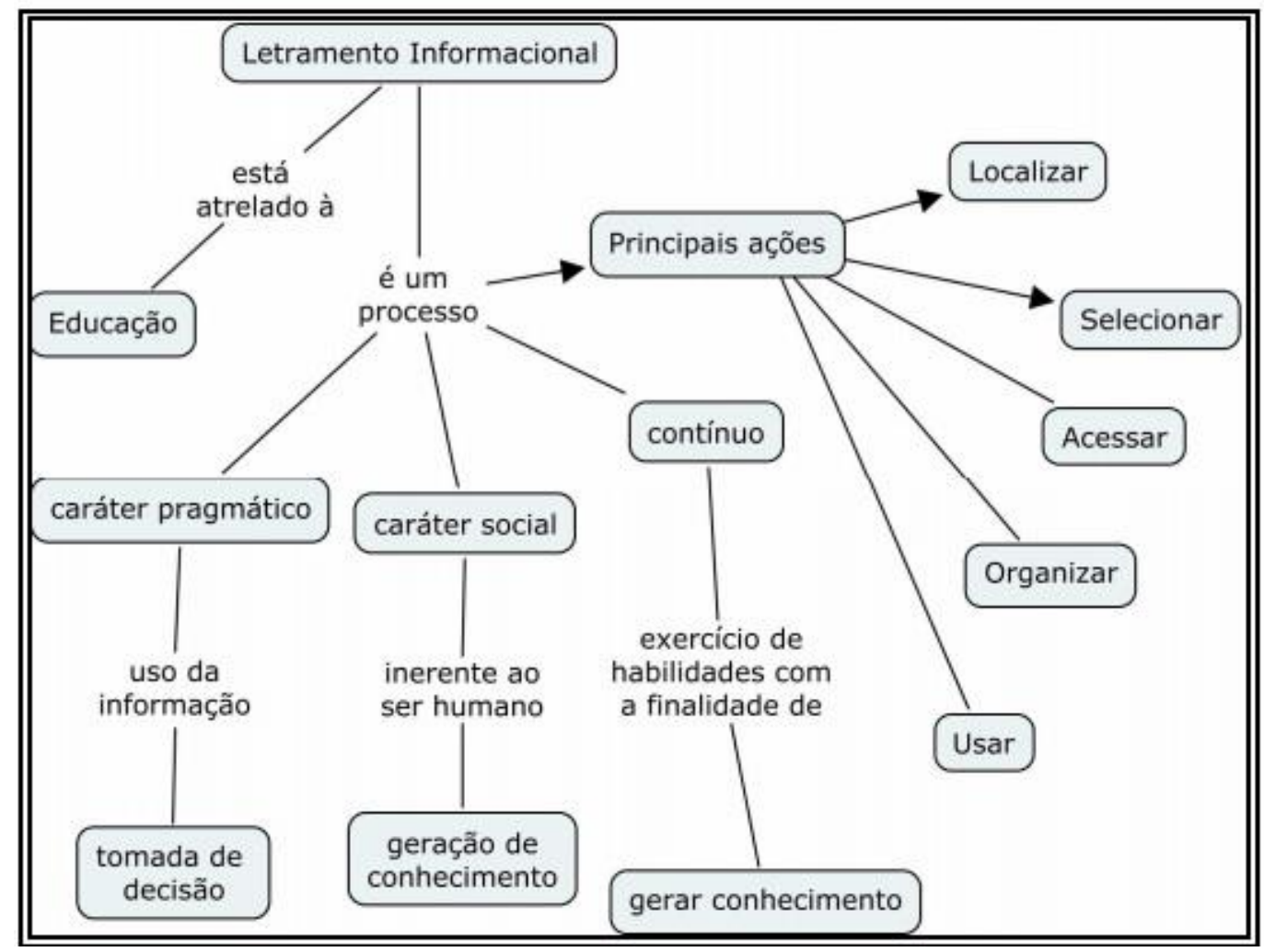

Fonte: SIQUEIRA; SIQUEIRA (2012)

A partir dos conceitos de information literacy, defendidos por Campello (2009b); Gasque (2010; 2013); Siqueira; Siqueira (2012), o termo letramento informacional foi adotado no desenvolvimento da pesquisa. Tal decisão levou em consideração que a investigação se refere ao processo de formação do indivíduo, levando-se em conta a diversidade de perfis e modalidades de ensino dos usuários atendidos pelas bibliotecas dos campi do Ifes. Tais sujeitos necessitam ter autonomia no que se refere a buscar, acessar e recuperar a informação em quaisquer ambientes e/ou suportes informacionais, em papel e eletrônicos, bem como em ambientes físicos e virtuais, para a resolução de problemas ou tomadas de decisão, aplicando a informação para a geração de conhecimento.

O letramento informacional é pré-requisito para o êxito da aprendizagem centrada no estudante e sua autonomia. Busca focalizar as competências, permitindo assim que o indivíduo adquira hábitos de leitura e atualização constante, a partir do uso adequado das ferramentas e estratégias de busca informacional, além de contribuir para o desenvolvimento do pensamento crítico e responsável em relação à atuação na sociedade, sendo essencial para o aprendizado ao longo da vida. 


\subsection{Educação de usuários}

No que se refere à educação de usuários, Dudziak, Gabriel e Villela (2000, p. 7-8) discorrem que,

[...] o paradigma teórico pedagógico deve se centralizar no aprendizado significativo, onde o estudante deve saber como o conhecimento é organizado, como achar a informação, como usá-la, para depois tornar-se apto a buscar soluções e a produzir conhecimento. A pesquisa e a elaboração de projetos devem ser enfatizadas. Frente a este novo cenário, a educação de usuários é mais do que nunca uma necessidade.[...] a educação de usuários é um termo abrangente que reúne vários tipos de ferramentas que vão desde a instrução, o treinamento, a apresentação de interfaces amigáveis, o marketing, a divulgação de artigos e reportagens, manuais, tours, cursos de acesso a bases de dados, até orientação bibliográfica.

Os serviços de referência, de tratamento técnico, de formação e desenvolvimento de coleção, entre outros, fazem da educação de usuários um serviço de acolhimento ao usuário de unidades de informação, principalmente nas bibliotecas, envolvendo múltiplas atividades. A educação de usuários é um serviço meio que tem como finalidade última tornar os indivíduos autossuficientes em lidar com a informação.

As Diretrizes do Manifesto da International Federation of Library Association (IFLA) de 2002 sobre a Internet estabelecem que a formação de usuários, os programas de acesso à Internet das bibliotecas e dos serviços de informação sob a responsabilidade dos bibliotecários, visam facilitar e promover o acesso público à informação e comunicação de qualidade. Os usuários devem ser auxiliados a adquirir as habilidades necessárias e deve ser fornecido um ambiente adequado para usar as fontes de informação e serviços escolhidas livre e confidencialmente (INTERNATIONAL..., 2002). O manifesto enfatiza fortemente que é o profissional bibliotecário o responsável para ensinar os usuários a adquirir tais competências.

O avanço tecnológico da comunicação e a diversidade de fontes de informação presentes na atualidade abrem caminho para o planejamento de ações de adequação dos serviços das bibliotecas, principalmente os planos que visam atender as necessidades dos usuários. As necessidades e demandas mudaram, assim como a forma de acessar e recuperar as informações tendem a mudar constantemente, provocando em muitos casos dificuldade e ansiedade na busca e construção do conhecimento. 
Contudo, nas palavras de Kuhlthau (1993), somente planejar melhores formas de orientar o usuário quanto a fontes e tecnologias não resolve adequadamente os problemas relacionados às barreiras no acesso, busca e recuperação da informação. O preenchimento da lacuna que existe entre o que o usuário necessita saber e o que ele sabe de fato, requer uma educação de usuários que envolva o uso, a interpretação e a busca de significados da informação e não apenas a busca de respostas a perguntas.

Cunha, Amaral e Dantas (2015) afirmam que os métodos, técnicas e modelos utilizados como procedimentos metodológicos na pesquisa de estudo de usuários da informação têm sido inadequados na sua maior parte. Assim o dizem, por entenderem que não estão sendo compreendidas as reais necessidades do usuário, essas que são inerentes não somente aos serviços de informação, mas ao meio no qual vivem e do qual recebem informações variadas, o que colabora para a formação de sujeitos diversos, com necessidades que não são estanques.

Com isso, considera-se então que uma verdadeira educação de usuários, visando o letramento informacional, deve envolver novas formas de auxiliar o usuário a construir seus próprios pensamentos e soluções às suas necessidades e demandas informacionais, desenvolvendo o espírito crítico e a autonomia na busca e recuperação da informação, prérequisitos para o desenvolvimento do letramento informacional.

Nesse sentido, o bibliotecário deve estar atento a buscar ações formativas de acordo com as necessidades e demandas do usuário a que atende. A educação de usuários deve ser concebida como um conjunto de atividades que proporcionam ao usuário um novo modelo de comportamento frente ao uso das bibliotecas e sistemas de informação, as fontes de informação disponíveis: os variados dispositivos disponíveis nas unidades ou sistemas de informação, instruindo constantemente o usuário para interagir com todas as possíveis fontes de informação (SANTIAGO; AZEVEDO NETTO, 2012).

Destarte, o planejamento de tais atividades deve ser realizado a partir de programas de educação de usuários, que partem da diversidade de interesses e de conhecimentos prévios e que motivam os usuários a utilizar os recursos informacionais presentes nas bibliotecas ou sistemas de informação, estejam onde estiverem, independentemente de seu suporte.

No entanto, para que as atividades voltadas para os usuários alcancem os objetivos propostos, é necessário que o profissional da informação se conscientize do seu papel educativo 
no uso das atuais fontes de informação e seja protagonista na construção de um trabalho colaborativo, principalmente com os docentes e dirigentes das instituições.

Para que isso seja atingido, torna-se necessário que a postura do profissional bibliotecário, especialmente de instituições de ensino, tenha um viés educador, não como um professor da educação formal de ensino médio ou universitário, por exemplo, mas o educador daquilo que ele sabe, o seu fazer bibliotecário: o acesso, busca e uso dos suportes, fontes, sistemas e redes informacionais. Afinal, o interesse precípuo do usuário docente e o discente é o mesmo da instituição em que ambos se encontram e interagem.

\section{Procedimentos metodológicos}

Para o desenvolvimento da pesquisa, foi realizada uma análise da literatura relacionada com a temática no contexto geral das bibliotecas dos Institutos Federais objetivando, desde uma perspectiva mais ampla, abordar o âmbito de estudo do letramento informacional. O estudo sustenta-se numa revisão de literatura, e numa descrição do papel da biblioteca e dos bibliotecários, atuantes nesses espaços, envolvidos no contexto do processo de letramento informacional, sua procedência e aplicação, e assim, identificar o seu impacto na melhoria dos serviços prestados aos usuários, particularmente os estudantes.

\subsection{Pesquisas sobre as bibliotecas dos Institutos Federais}

A inquietação a respeito das bibliotecas dos Institutos Federais (IF) surgiu praticamente quando essa instituição foi criada, em 2008. Apesar dessa modalidade de bibliotecas ser recente, vem se observando na produção da literatura dos programas de pós-graduação e nas temáticas de encontros da área, bibliotecários lotados nos institutos procurando por melhores formas de buscar e levar conhecimento específico para tão complexas unidades de informação. Tais bibliotecas, na configuração que hoje apresentam quanto à diversidade de usuários, já nasceram no limiar das mudanças observadas por outras unidades de informação ligadas principalmente ao ensino médio e às universidades nas quais o conhecimento e as mudanças ocasionadas pelas novas tecnologias da informação estão mais presentes. São apresentados a seguir, dois estudos acadêmicos, escolhidos principalmente por serem recentes e pela ampla abrangência do objeto pesquisado.

InCID: R. Ci. Inf. e Doc., Ribeirão Preto, v. 11, n. 2, p. 121-141, set. 2020/fev. 2021. 
Moreira (2018) propôs-se a apreender a visão do bibliotecário acerca das perspectivas e desafios presentes no exercício da sua prática educativa, tendo em vista a instituição dos sistemas/redes de bibliotecas dos Institutos Federais. Por meio de questionários e de entrevistas semiestruturadas com os bibliotecários no âmbito dos 38 IF existentes, a escolha dos institutos para participação na aplicação da pesquisa seguiu o critério de possuírem sistema de bibliotecas e bibliotecários. Foram identificados 14 sistemas e quatro redes de bibliotecas formalmente instituídos - outros 20 Institutos não possuíam suas bibliotecas organizadas ou estruturadas. A amostra se restringiu, então, aos bibliotecários das unidades que retornaram à solicitação, a saber: IFAM, IFB, IFBA, IFC, IFG, IFGoiano, IFPB, IFRS, IFSC, IFSP e IFSertão. O questionário foi enviado aos 289 bibliotecários atuantes nas instituições acima mencionadas, com retorno de 89 respostas, quantitativo equivalente a $31 \%$ do total de questionários enviados. Por sua vez, as entrevistas semiestruturadas foram desenvolvidas com dez bibliotecários, sendo cinco coordenadores dos sistemas/redes de bibliotecas.

Segundo o autor, foi possível identificar que o maior desafio relatado pelos sujeitos entrevistados é o número insuficiente de pessoal, principalmente de bibliotecários. Tal fato, ainda segundo os relatos, acarreta prejuízos ao desenvolvimento das atividades das bibliotecas, sobretudo da ação educativa, pois os bibliotecários têm que priorizar as atividades técnicas de rotina, como a catalogação e a circulação de materiais. Alegam que tais atividades impactam no funcionamento do setor. Também foi possível averiguar que as bibliotecas não estão preparadas para atender as demandas específicas da diversidade, visto que os sujeitos da educação à distância e as pessoas com deficiências não são contempladas efetivamente pelos serviços oferecidos, devido às restrições de ordem estrutural, material e organizacional.

O outro estudo que também objetivava avaliar as condições de funcionamento das bibliotecas dos Institutos Federais foi desenvolvido por Proença (2018). Essa pesquisa visava conhecer as condições de funcionamento de 102 bibliotecas de quatro Institutos Federais: IFG, IFSC, IFSP e o IFC. Aplicou-se um questionário eletrônico a todos os bibliotecários e auxiliares de bibliotecas e obteve-se a taxa de retorno de 64\%. Em relação às atividades implementadas pelos bibliotecários para o desenvolvimento da ação educativa de usuários, as práticas compreendem visitas guiadas à biblioteca direcionadas aos novos alunos, com vistas à familiarização deles em relação aos espaços, acervos, recursos e serviços; capacitações para realizar pesquisas no catálogo e para localização de itens do acervo; formação para uso das bibliotecas virtuais e bases de dados de livros e periódicos; orientação quanto à normalização 
de trabalhos acadêmicos e citação e referências de documentos, no que se refere às normas da ABNT; ações de incentivo à leitura, atividades culturais, além das atividades habituais de circulação de materiais informacionais.

Entretanto, o autor destaca que as práticas da educação de usuários precisam ser mais sistematizadas em todas as unidades dos sistemas/redes de bibliotecas dos IF que fizeram parte da pesquisa. De acordo com o pontuado pelos bibliotecários nas entrevistas, alguns profissionais não desenvolvem as ações educativas de usuários a contento do esperado, seja por questões de infraestrutura ou por questões formativas. Nesse sentido, a abordagem da ação educativa do bibliotecário, neste trabalho, possibilitou assinalar que as práticas educativas de usuários tão consagradas no âmbito das bibliotecas precisam ser repensadas, tendo em vista que os anseios de aprendizagem dos sujeitos confrontam-se com as novas exigências ambientais, sejam estas tecnológicas, políticas, econômicas, sociais, educacionais e culturais. Ainda segundo Proença (2018), ficou claro que, em geral, os bibliotecários agem de maneira "amadora", confiando-se muito nos saberes experienciais advindos da prática cotidiana de trabalho para a implementação das ações, dispensando-se o planejamento.

\subsection{Metodologia da pesquisa no Ifes}

A pesquisa teve por objetivo, primordialmente, verificar o papel do bibliotecário como agente de promoção do letramento informacional dos estudantes do Ifes, sua participação nas atividades de ensino e aprendizagem, além de buscar compreender o seu trabalho, principalmente com os professores, nos processos de formação e uso eficiente das informações disponíveis para esses estudantes.

Com relação à metodologia, a pesquisa junto às bibliotecas do Ifes foi um estudo de caso com caráter descritivo e de natureza qualitativa-quantitativa. Foi escolhida duas bibliotecas que atendem a um público, embora diversificado, possuem características semelhantes (estudantes regularmente matriculados nas diversas modalidades de ensino do Ifes), "documentando-se as diversidades, sem intencionalidade de localizar as diferenças e coincidências" (YIN, 2001; DENZIN; LINCOLN, 2006). Para tanto, optou-se como ferramenta de coleta de dados entrevistas semiestruturadas com os bibliotecários e o questionário eletrônico para todos os estudantes maiores de dezoito anos, que fazem parte dos dois campi previamente escolhidos. 
Para um melhor entendimento a respeito do critério de seleção dos campi participantes da pesquisa, foi realizado inicialmente um recorte com os seguintes critérios representativos: i) Identificar todos os campi do Ifes; ii) identificar o quantitativo de cursos regulares oferecidos em cada campi; iii) quantificar o total de matrículas presenciais oferecidas em cada campi.

Para operacionalizar a realização da pesquisa, optou-se por determinar os seguintes critérios de seleção:

a) campi com aspectos históricos geográficos tais como: localização geográfica e tempo de funcionamento;

b) campi com oferta decursos nas modalidades: técnico integrado ao ensino médio, técnico concomitante e/ou subsequente, graduação, pós-graduação e Proeja;

c) bibliotecas que contemplem condições e realidades socioculturais e demográficas diversificadas de estudantes;

d) tempo de funcionamento da biblioteca no campus.

Por se tratar de uma instituição multicampi presente em todas as regiões do Espírito Santo, contabilizando 22 campi em funcionamento, optou-se pela amostragem intencional que, segundo Cunha, Amaral e Dantas (2015), possibilita ao pesquisador selecionar os elementos aos quais tem acesso, admitindo que esses possam de alguma forma, representar o universo, além de ser muito usada por ser menos onerosa para o pesquisador. A partir dos critérios de seleção das unidades de análise acima elencados e de uma pesquisa criteriosa no site do Ifes, no qual foi possível acessar as informações que respondessem aos critérios de seleção, foram escolhidas as bibliotecas dos seguintes campi: campus Santa Teresa, localizado na região serrana do Espírito Santo e campus Vitória, localizado na capital do Estado.

Para analisar os dados, optou-se por uma triangulação de métodos (DENZIN, LINCOLN, 1989; YIN, 2001), que instituiu um modus operandi pautado na articulação das informações concretas levantadas com a pesquisa, quais sejam: os dados empíricos, as narrativas dos entrevistados (bibliotecários); do diálogo com os autores que estudam a temática em questão para instituir o traçado interdisciplinar do marco teórico e; da análise de conjuntura, que compreende o contexto mais amplo e mais abstrato do fenômeno do letramento informacional das bibliotecas do Ifes, por meio da aplicação de questionário aos discentes. 
A equipe do campus de Vitória é composta por sete bibliotecários, sendo que cinco consentiram em participar da entrevista. Já o campus de Santa Teresa possui dois bibliotecários, e ambos concordaram em participar da entrevista. O segmento discente reúne alunos dos cursos técnico integrado ao ensino médio, técnico subsequente e concomitante, graduação e pósgraduação (stricto sensu e lato sensu). Foram encaminhados 4.235 questionários para os estudantes maiores de 18 anos regularmente matriculados nos cursos presenciais ofertados pelos campi de Santa Teresa e Vitória; 12 questionários não foram entregues devido a algum erro no e-mail cadastrado, desta forma, 4.223 questionários foram enviados e entregues aos seus destinatários (estudantes).

Como se tratou de uma pesquisa voluntária, dos 4.223 questionários enviados, houve um retorno de 807 questionários, representando 19\% do universo da pesquisa. Desse número de questionários retornados, 500 questionários foram respondidos de forma completa, representando $62 \%$ e 307 foram respondidos de forma incompleta, representando $38 \%$ da quantidade total da amostra retornada. Para a análise da pesquisa, foram considerados os questionários respondidos de forma completa: 500 questionários (62\% da amostra retornada).

\subsection{Resultados alcançados}

As entrevistas semiestruturadas aconteceram nas bibliotecas objeto da pesquisa nos dias previamente agendados com os profissionais. As perguntas foram norteadoras para que os relatos a respeito da percepção sobre letramento informacional, a participação dos bibliotecários nas atividades pedagógicas dos campi, assim como as competências e responsabilidades necessárias do profissional para o desenvolvimento de atividades para os estudantes visando o letramento informacional fossem respondidas pelos participantes. A participação dos bibliotecários na entrevista individual ocorreu após a assinatura do Termo de Consentimento Livre e Esclarecido, sem intercorrências e todos os participantes se mostraram a vontade com as questões levantadas.

De acordo com os dados das entrevistas, foi constatado que cinco dos sete bibliotecários entrevistados ingressaram no Instituto a partir da reestruturação da Rede Federal, que aconteceu em 2008. A preocupação com a formação continuada além das atividades tecnicistas está presente no discurso dos bibliotecários, pois acreditam que a constante atualização e aprimoramento promovem a melhoria nos serviços ofertados nas bibliotecas dos campi, bem 
como possibilitam um trabalho integrado com o professor. Porém, a participação em atividades de formação continuada não foi complementada por relatos que se concretizassem em ações planejadas, visando a melhoria das práticas educativas, dentre outras questões que envolvam o letramento informacional. Apesar da preocupação com a qualidade dos serviços, ainda é tímida a participação dos bibliotecários nas atividades pedagógicas.

Outra questão dizia respeito à responsabilidade profissional do bibliotecário no auxílio aos usuários no atendimento das demandas informacionais. Notou-se, também, que embora reconheçam a importância da formação dos usuários, os bibliotecários do campus Santa Teresa relataram que não realizam ações formativas de nenhuma natureza; em contrapartida, os bibliotecários do campus Vitória informaram que realizam formação de usuários, ainda que não haja uma rotina em tais atividades.

A respeito do nível de reconhecimento dos bibliotecários quanto ao atributo do letramento informacional, foi possível perceber por intermédio da pesquisa que o termo é conhecido por todos os bibliotecários entrevistados, que reconhecem o letramento informacional como o processo de acessar, buscar, recuperar e usar a informação de forma autônoma. Também reconhecem a importância de desenvolver essa autonomia por meio de atividades e serviços oferecidos pela biblioteca ou outras unidades informacionais, para que os usuários possam utilizar a informação de forma que ela se transforme em conhecimento. Contudo, não foi observado nenhum projeto específico realizado pelos bibliotecários do Ifes, visando o desenvolvimento do letramento informacional dos estudantes, bem como o planejamento para atender às demandas informacionais diversificadas, visando o uso eficiente das informações obtidas pelos estudantes.

Com relação à participação dos bibliotecários na elaboração das atividades pedagógicas presentes nos campi do Ifes, foi constatado pelas entrevistas que essa participação praticamente não existe, ficando em muitos casos relegada apenas à conferência das bibliografias presentes nos projetos pedagógicos dos cursos. Segundo relatos dos entrevistados, a postura da instituição, em especial do setor pedagógico e da direção de ensino, percebe o bibliotecário como um profissional tecnicista, suas atividades e serviços encontram-se ligados apenas ao manejo dos materiais informacionais e o espaço da biblioteca como um local para estudar.

No que concerne às formações rotineiras voltadas para a educação de usuários e o desenvolvimento do letramento informacional dos estudantes oferecidos pelas bibliotecas 
pesquisadas, foi constatado que os bibliotecários sabem da importância que tais formações têm para a aquisição de habilidades para trabalhar com a educação de forma eficaz. Contudo, um projeto implementado de capacitação não é uma realidade nos campi. Na biblioteca do campus Santa Teresa, de acordo com os bibliotecários entrevistados, não há ações formativas voltadas para a educação de usuários. Já na biblioteca do campus Vitória há ações formativas, porém, elas não são ofertadas para todos os estudantes, estão mais voltados para o uso do Portal de Periódicos da CAPES e dos cadernos de elaboração de trabalhos acadêmicos e referências. Essas capacitações atendem apenas os estudantes de graduação e pós-graduação e são oferecidos sob demanda dos cursos.

A aplicação do questionário eletrônico aos estudantes aconteceu entre os dias 2 de setembro e 2 de outubro de 2019. As perguntas que constavam no questionário foram feitas de forma a responder os objetivos da pesquisa, assim como, identificar a percepção dos estudantes em relação às atividades e serviços ofertados pelas bibliotecas do Ifes. As questões foram elaboradas com a intenção dos participantes responderem aos seguintes questionamentos: frequência à biblioteca, conhecimento e participação nas ações formativas oferecidas pela biblioteca; conhecimento e utilização dos serviços oferecidos pela biblioteca.

Para a análise da pesquisa, foram considerados os questionários respondidos de forma completa: 500 questionários (62\% da amostra retornada) dentre 807 questionários. As categorias de análises foram as próprias perguntas e os resultados alcançados refletiram a percepção dos estudantes a respeito dos temas abordados nesta pesquisa. Dentre os resultados mais importantes obtidos cita-se, primeiramente, o desconhecimento de técnicas e ferramentas de busca da informação mais apuradas e específicas para cada área do conhecimento, além da consulta simples a internet. Mais enfaticamente, verificou-se o desconhecimento por parte dos respondentes de que os bibliotecários possuem a competência para fornecer formalmente tais ensinamentos e serviços, como minicursos permanentes e auxílio pessoal, para capacitá-los a desenvolver, de forma independente, o letramento informacional; e que eles podem demandar à biblioteca tais serviços. 


\section{Considerações finais}

$\mathrm{O}$ interesse em pesquisar o letramento informacional no contexto das bibliotecas do Ifes se deve ao fato que até hoje existe pouca informação, projetos de identificação do papel das bibliotecas da instituição como agente de promoção do letramento informacional dos estudantes, no intuito de melhorar os serviços prestados pelas bibliotecas, além de estabelecer as bases para uma melhor educação de usuário, tendo principalmente o bibliotecário como educador. A pesquisa documental, a procura de registros nos institutos sobre projetos, propostas de ações das bibliotecas não devolveu resultados.

Uma das análises que mais chamou atenção no questionário foi a que dizia respeito à falta de conhecimento das atividades promovidas pelas bibliotecas, inclusive no campus Vitória. Os estudantes relataram que não existe uma divulgação eficiente e que tal fato certamente inviabilizou a participação nas atividades.

A partir dessa realidade, verifica-se que o corpo de bibliotecários precisa assumir uma postura mais proativa e ter como prioridade a elaboração de plano de trabalho anual, aprovado pelos dirigentes do campus no qual trabalham, constando em tal plano os projetos que irão oferecer a todos os estudantes, com o intuito de promover o letramento. Projetos que visem implementar uma rotina de atividades de ações formativas para os estudantes, referentes às ferramentas disponíveis atualmente nas bibliotecas, além de atividades visando a aquisição de habilidades no uso da informação: atividades que estimulem o processo de desenvolvimento do letramento informacional dos estudantes.

A realização das ações formativas deve ser adotada para todos os estudantes de todas as modalidades de ensino, levando em consideração as necessidades informacionais de cada modalidade e deve vir acompanhada de uma ampla divulgação, para que os estudantes possam participar.

A adoção de formações para os estudantes do Ifes no que diz respeito às ferramentas disponíveis para o desenvolvimento das suas atividades acadêmicas, farão que os usuários reconheçam a aplicabilidade dos serviços que as bibliotecas ofertam e de forma a auxiliar no desenvolvimento de habilidades para a o uso da informação de forma crítica e reflexiva. A adoção de uma disciplina na qual o bibliotecário possa trabalhar de modo colaborativo com os docentes, com o objetivo de desenvolver habilidades de acesso, busca, recuperação e uso da 
informação de forma satisfatória pode ser considerada, com o objetivo de tornar os estudantes autossuficientes no uso da informação.

O plano de atividades deve também prever a forma de difusão das ações formativas e também dos serviços rotineiros oferecidos pelas bibliotecas, haja vista o desconhecimento apresentado pela comunidade do potencial do profissional bibliotecário e da própria instituição biblioteca. O conhecimento dos serviços e atividades promovidas pelas bibliotecas por parte dos estudantes, docentes e demais agentes da instituição deve ser promovido, também, como estratégia para reverter esse quadro de desconhecimento. Certamente tais atitudes promoverão o reconhecimento necessário da real capacidade do bibliotecário, principalmente como educador das habilidades de recuperação de informações. A maior aproximação com os estudantes e professores é a ação que reverterá a figura do bibliotecário tecnicista e passivo e a biblioteca sendo apenas um espaço onde se pode estudar e "pegar livros", realidade hoje observada nos campi do Ifes.

Um dos caminhos a ser percorrido para alcançar o objetivo de o bibliotecário atuar também como educador, é a realização de trabalho conjunto com os professores. A falta de um trabalho integrado pode, também, estar ligada à ausência de política educacional, na qual o bibliotecário atuaria de forma mais ativa nas atividades que envolvem o ensino dentro e fora da sala de aula. Com isso, o trabalho do bibliotecário como educador não faz parte do cotidiano dos estudantes.

O trabalho colaborativo entre o bibliotecário e o professor tem a possibilidade de mudar a visão, não só do estudante, mas de toda a instituição a respeito da função educativa do bibliotecário. Para que o letramento informacional se efetive de fato junto aos estudantes, há a necessidade de um movimento de corresponsabilidade entre os agentes que fazem parte do processo de ensino, sejam eles os bibliotecários, docentes, pedagogos e demais agentes da instituição de ensino.

A pesquisa realizada nos campi do Ifes trouxe um rico material a respeito das percepções dos bibliotecários sobre a importância do desenvolvimento do letramento informacional nos estudantes. A partir das entrevistas foi possível entender a dinâmica das atividades realizadas pelos profissionais no que tange ao atendimento às necessidades informacionais dos estudantes, bem como os percalços e dificuldades que passam os bibliotecários no seu fazer diário. 
Quanto aos estudantes, a contribuição valorosa e sincera nas respostas trouxe luz ao caminho que ainda precisa ser percorrido, para que o bibliotecário possa ser reconhecido como um profissional ligado à educação de uma forma mais direta e que a biblioteca possa ser vislumbrada como um espaço de educação e geração de conhecimento nos Institutos Federais, pois se trata de um público com uma diversidade de ensino bem singular dentro do escopo da educação no Brasil.

A ampla compreensão da promoção do letramento informacional e seus desdobramentos em bibliotecas que ainda buscam uma identidade própria como dispositivo informacional, clamam pela urgente incorporação da temática na agenda de estudos da Biblioteconomia e da Ciência da Informação. Quanto aos sistemas e redes das bibliotecas dos Institutos Federais de Educação, Ciência e Tecnologia já existentes, indica-se a necessidade da abertura de um espaço para reflexão acerca da prática didático-pedagógica do bibliotecário, focado no contexto e na constituição específica da referida instituição de ensino. Reconhece-se que é um desafio buscar a convergência de saberes biblioteconômicos, no intuito de planejar de maneira integrada e cooperativa as ações frente às finalidades e objetivos da instituição de ensino, tendo ainda como objetivo suplementar, o fortalecimento da presença do bibliotecário e da biblioteca na aprendizagem dos estudantes dos Institutos Federais. 


\section{Referências}

AZEVEDO, Kelly Rita de. Letramento informacional em bibliotecas do Instituto Federal do Espírito Santo: o trabalho do bibliotecário frente às demandas e necessidades informacionais dos estudantes. Dissertação (Mestrado em Ciência da Informação) - Programa de Pós-graduação em Ciência da Informação, Universidade Federal de Minas Gerais, Belo Horizonte, 2020.

CAMPELLO, Bernadete Santos. A função educativa da biblioteca escolar no Brasil: perspectivas para o seu aperfeiçoamento. In: ENCONTRO NACIONAL DE PESQUISA EM CIÊNCIA DA INFORMAÇÃO, 5., Belo Horizonte, 2003. Anais [...] Belo Horizonte: Escola de Ciência da Informação da UFMG, 2003. Disponível em:

http://enancib.ibict.br/index.php/enancib/venancib/paper/viewFile/1927/1068. Acesso em: 15 jun. 2019.

CAMPELLO, Bernadete Santos. Letramento informacional: função educativa do bibliotecário na escola. Belo Horizonte: Autêntica, 2009a.

CAMPELLO, Bernadete Santos. Letramento informacional no Brasil: práticas educativas de bibliotecários em escola de ensino básico. 2009. 208 f. Tese (Doutorado em Ciência da Informação) - Programa de Pós-graduação em Ciência da Informação, Universidade Federal de Minas Gerais, Belo Horizonte, 2009b. Disponível em: http://hdl.handle.net/1843/ECID7UUPJY. Acesso em: 01 jul. 2019.

CUNHA, Murilo Bastos da; AMARAL, Sueli Angélica do; DANTAS, Edmundo Brandão. Manual de estudo de usuários da informação. São Paulo: Atlas, 2015.

DENZIN, Norman K.; LINCOLN, Yvonna S. The research act. Englewood Cliffs N. J.: Prentice Hall, 1989.

DENZIN, Norman K.; LINCOLN, Yvonna S. O planejamento da pesquisa qualitativa: teorias e abordagens. 2. ed. Porto Alegre: Penso, 2006.

DUDZIAK, Elisabeth Adriana; GABRIEL, Maria Aparecida; VILLELA, Maria Cristina Olaio. A educação de usuários de bibliotecas universitárias frente à sociedade do conhecimento e sua inserção nos novos paradigmas educacionais. In: SEMINÁRIO NACIONAL DE BIBLIOTECAS UNIVERSITÁRIAS, 11.,2000, Florianópolis. Anais [...] Florianópolis: UFSC, 2000. Disponível em: https://www.bu.ufmg.br/snbu2014/anais_anterior/XI-SNBU/Dados/TrabLiv/t060.pdf. . Acesso em: 10 jul. 2020.

GASQUE, Kelley C. G. D. Arcabouço conceitual do letramento informacional. Ciência da Informação, Brasília, v. 39 n. 3, p.83-92, 2010. Disponível em: http://www.scielo.br/pdf/ci/v39n3/v39n3a07.pdf. Acesso em: 7 jan. 2019.

GASQUE, Kelley C. G. D. Competência em informação: conceitos, características e desafios. AtoZ: Novas Práticas em Informação e Conhecimento, Curitiba, v. 2, n. 1, p. 5-9, 2013. Disponível em: https://revistas.ufpr.br/atoz/article/view/41315. Acesso em: 27 maio 2019. 
INTERNATIONAL FEDERATION OF LIBRARY ASSOCIATIONS AND INSTITUTION. Diretrizes para o manifesto IFLA/UNESCO sobre a internet. 2002. Disponível em: https://www.ifla.org/files/assets/faife/publications/policy-documents/internet-manifestopt.pdf. Acesso em: 14 jun. 2019.

KUHLTHAU, Carol Collier. Seeking meaning: a process approach to library and information services. Norwood: Ablex Pub, 1993.

MONTIEL-OVERALL, P. A theoretical understanding of teacher and librarian collaboration (TLC). School Libraries Worldwide, v. 11, n. 2, p. 24-48, 2005. Disponível em: https://pdfs.semanticscholar.org/e7c7/907d2ef3e7ea7babf67b0d13e4fb2b2f5717.pdf. Acesso em: 23 jun. 2019.

MOREIRA, Cesar dos Santos. Ação educativa dos bibliotecários: um repensar da sua práxis profissional nos institutos federais. 2018. Dissertação (Mestrado em Ciência da Informação) - Programa de Pós-graduação em Ciência da Informação, Universidade Federal de Minas Gerais, Belo Horizonte, 2018. Disponível em: http://hdl.handle.net/1843/VAFABB4HUR. Acesso em: 20 dez. 2019.

PROENÇA, Samuel Gonçalves. Bibliotecas dos Institutos Federais de Educação, Ciência e Tecnologia: uma avaliação de suas condições de funcionamento. Dissertação (Mestrado em Ciência da Informação) - Programa de Pós-graduação em Ciência da Informação, Universidade Federal de Minas Gerais, Belo Horizonte, 2018. Disponível em: http://hdl.handle.net/1843/BUOS-B68EL9. Acesso em: 20 dez. 2019.

SANTIAGO, Sandra Maria Neri; AZEVEDO NETTO, Carlos Xavier de. Educação de usuários: um estudo junto ao sistema integrado de bibliotecas da UFPE. Revista ACB: Biblioteconomia em Santa Catarina, Florianópolis, v. 17, n. 2, p. 246-268, 2012. Disponível em: https://revista.acbsc.org.br/racb/article/view/835. Acesso em: 18 ago. 2019.

SIQUEIRA, Ivan Cláudio Pereira; SIQUEIRA, Jéssica Câmara. Information literacy: uma abordagem terminológica. In: ENCONTRO NACIONAL DE PESQUISA EM CIÊNCIA DA INFORMAÇÃO, 13., 2012, Rio de Janeiro. Anais [...]. Rio de Janeiro: Fiocruz, 2012.

Disponível em:

http://repositorios.questoesemrede.uff.br/repositorios/handle/123456789/1340. Acesso em: 29 nov. 2019.

SOARES, Magda. Letramento: um tema em três gêneros. 3. ed. Belo Horizonte: Autêntica, 2009.

YIN, Robert K. Estudos de casos: planejamento e métodos. 2. ed. Porto Alegre: Bookman, 2001 . 